\title{
AUDIT REPORT
}

\section{THE \\ DEPARTMENT OF ENERGY'S PEER REVIEW PRACTICES}

APRIL 1998

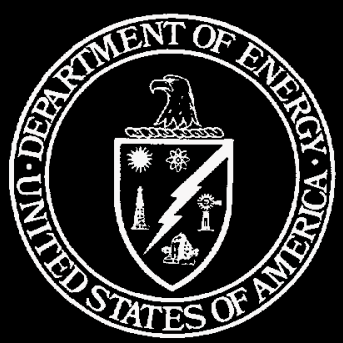

U.S. DEPARTMENT OF ENERGY JFFICE OF INSPECTOR GENERAL OFFICE OF AUDIT SERVICES
DSTIBUTION OP TMI DOCUMENT IS UNLIPATEB

\section{MASTER}




\section{DISCLAIMER}

Portions of this document may be illegible electronic image products. Images are produced from the best available original document. 


\section{Department of Energy}

Washir.gton, DC 20585

April 6, 1998

\section{MEMORANDUM FOR THE SECRETARY}

FROM:

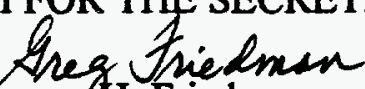

Gregoryth. Friedman

Acting Inspector General

SUBJECT: INFORMATION: Audit Report on "The Department of Energy's Peer Review Practices"

\section{BACKGROUND}

Fulfilling the requirements of the Government Performance and Results Act of 1993 has presented Federal science agencies with the challenge of defining ways to quantify and evaluate the outcomes of research. Measuring research program performance is particularly important for the Department of Energy because of its substantial investment (approximately $\$ 7$ billion in Fiscal Year 1996) in research and development activities.

The Research Roundtable, in 1995, observed that the results of research could be evaluated using the performance indicators of relevance, productivity, and quality. One method for doing so is formal, objective evaluation by independent reviewers, or peer review. The objective of the audit was to determine whether the Department had established and was managing a peer review process for evaluating scientific and technical projects.

\section{RESULTS OF AUDIT}

Peer review programs had been established to manage various research and development activities at the Department's National Renewable Energy Laboratory and the Pacific Northwest and Los Alamos National Laboratories. We found that peer reviews were conducted prior to competitive award of subcontracts, selection of projects from research proposals, and inclusion in scientific journals and/or conferences. In addition, the Department and the laboratories, in response to the Government Performance and Results Act and performance-based contracting, had incorporated peer review into the laboratories' annual performance self-assessment process. The results of these reviews were used to determine program direction, obtain input on ongoing programs, and prioritize funding for laboratory and Departmental research activities.

This report does not include any recommendations since the laboratories had established processes in accordance with Office of Management and Budget and Departmental peer review 
requirements. The audit included only three of 20 laboratories that received Departmental research and development funding in FY 1996. Therefore, there is no assurance that our conclusions can be extended to the peer review practices at all DOE laboratories or research programs.

Attachment

cc: Deputy Secretary

Under Secretary 
TABLE OF CONTENTS

\section{Overview}

The Department of Energy's Peer Review Process .

\section{DOE Peer Review Practices}

Results of Audit 3

\section{Appendix 1}

Scope and Methodology .9

\section{Appendix 2}

List of Peer Reviews 
INTRODUCTION AND OBJECTIVE
Recent laws enacted by the President and the Congress and program evaluation initiatives from the Office of Management and Budget (OMB) require Federal agencies, including agencies actively involved in scientific research, to develop annual performance plans. These plans should include suitable performance measures, document program outcomes, and use merit review with peer evaluation and competitive selection of Federal research and development (R\&D) projects. Measuring program performance is particularly important for the Department of Energy (DOE) because of its substantial investment ( $\$ 6.7$ billion in Fiscal Year 1996) in R\&D activities.

In 1995, the Research Roundtable, a group of Federal researchers and managers representing a cross-section of departments and agencies, concluded that the results of research program performance could be measured and evaluated using various assessment methods, including peer review, to determine the relevance, productivity, and quality of research activities.

Peer review is defined as a competent, qualified, objective, and formal evaluation by independent reviewers using specified criteria. As a scientific custom, peer review is an organized method for evaluating work that is used by scientists to certify the correctness of procedures, establish the plausibility of results, and allocate scarce resources such as research funds, special honors, and space in professional journals.

The Department emphasized its commitment to peer review in its 1994 and 1997 Strategic Plans. As a success indicator for its science and technology programs, the Department is committed to maintaining "the high quality and relevance of DOE's science as evaluated by annual peer reviews and advisory committees."

Peer review, in addition, plays a role in guiding the formation of research and development budgets. In 1994, the OMB, along with the White House, Office of Science and Technology Policy, issued a memorandum to Federal agencies that established peer review (merit review with peer evaluation) as an R\&D principle. In developing their Fiscal Year 1996 budgets, Federal agencies were advised to "significantly enhance the utilization of merit review with peer evaluation and competitive selection in Federal R\&D projects."

The objective of the audit was to determine whether the Department had established and was managing a peer review process for evaluating scientific and technical projects. 
CONCLUSIONS AND OBSERVATIONS
At the three laboratories where audit work was performed, the Department had established and was managing a peer review process for scientific and technical projects. The National Renewable Energy Laboratory (NREL), the Pacific Northwest National Laboratory (PNNL), and the Los Alamos National Laboratory (LANL) had instituted peer review programs in accordance with Administration policy and $\mathrm{OMB}$ requirements. In addition, the results of these reviews were being utilized to guide the R\&D activities at the laboratories for the following programs: Defense Programs, Energy Efficiency, Environmental Management, Energy Research, and Nuclear Nonproliferation and National Security.

Third-party reviewers performed peer reviews of laboratory divisions. In addition, customers, ranging from principal investigators to assistant secretaries, utilized peer review results to guide Department and laboratory R\&D activities. Results were used to determine program direction, obtain input on ongoing programs, and prioritize funding for projects based on research results. They were also considered as part of contractor self-assessments and Departmental performance evaluations.

Additionally, individual peer review committee members contacted during the course of the audit characterized the Department's peer review processes as an effective method for providing direction to the Department's R\&D activities. Committee members stated they were satisfied that the results of their peer review efforts were being considered by the laboratories and the Department.

This report does not contain recommendations since the three laboratories had established and were managing peer review processes. However, the audit examined only three of 20 Department laboratories that received R\&D funding in Fiscal Year 1996. Therefore, there is no assurance that our conclusions can be extended to the peer review practices at all DOE laboratories or research programs.

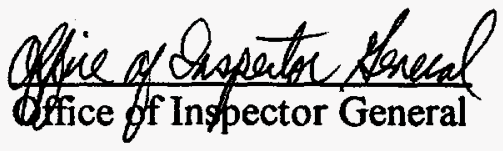




\section{Department And M\&O Contractors Required To Conduct Peer Reviews}

Administration R\&D policy principles issued by the White House, Office of Science and Technology Policy, direct Federal agencies to use merit review with peer evaluation (peer review) and competitive selection in R\&D projects. Chosen activities must be reviewed, in accordance with OMB Circular A-11, by appropriately qualified scientists and engineers outside the decision-making or supervisory chain.

Under the Government Performance and Results Act (Results Act) of 1993, Federal agencies are also required to establish long-term strategic goals, measure performance against those goals, and report publicly on how well they are doing. To facilitate this process, the Department of Energy has required its laboratories to develop a formal program to evaluate their research, science and technology, or scientific excellence and productivity programs. These evaluations, which are performed at least annually, are based on a combination of peer review and selfassessment.

The Department's 1994 and 1997 Strategic Plans underscored the importance of independent third-party reviews. In order to meet the Department's strategic goals for its science and technology, the Department plans to utilize peer review as a performance measure. Success in meeting its goals for science and technology would be indicated by favorable outside peer reviews and judgments of expert advisory committees.

The laboratories used peer review, and the outcomes of these reviews, as a mechanism to guide $R \& D$ programs and projects through their life cycle. With the advent of the Results Act and performance-based contracting, peer review had also become a part of the contractors' annual (or semi-annual) performance self-assessment and performance evaluation processes.

\section{Peer Review Practices}

As a scientific custom, peer review was being used by the three laboratories to guide their R\&D programs and projects. The peer review practices in place involved the competitive selection of subcontracts; submission of new research proposals; Departmental and other third party reviews; submission of scientific information at conferences or scientific journals, and determination of recognition and awards. For example, many of the programs reviewed at NREL 
included subcontracted activities. External program review and standing advisory committees served as technical peer review groups for competitive selection of these subcontracted projects. Peer review was also used to evaluate new proposals. At PNNL, the peer review process was designed to ensure that proposals had scientific quality and were targeted to key technology problems.

Peer review has also been a traditional aspect of the Department's and other third-party evaluations of the contractors R\&D activities. At NREL, the DOE Photovoltaics Division Director assessed the status, accomplishments, issues, and future directions for the NREL Photovoltaics Program. The laboratory used this assessment to develop a Draft Operating Plan that described NREL's strategy for supporting the DOE Photovoltaics program. New projects and programs at LANL were also subject to various peer reviews. To illustrate, the LANL research effort of Proton Radiography was reviewed in January and November of 1996 by external third party reviewers, as well as by the LANL Physics Division Advisory Committee. Appendix 2 provides a listing of the some of the peer reviews that occurred at the three laboratories in Fiscal Year 1996.

The publication of original work in the open literature constituted another form of peer review. The quality of written products by R\&D performers was evaluated by third-party reviewers prior to being accepted for publication in archival, peer-reviewed journals. Two of the laboratories compiled data on staff publications. Database searches conducted by LANL and PNNL for Fiscal Year 1996 showed 1,456 and 491 publications, respectively, in peer-reviewed journals. Listings of NREL publications were available for each research line-of-effort included in the review.

Research products of the laboratories were also subject to peer review by independent parties in the determination of recognition and awards. R\&D 100 Awards, for example, are provided to the 100 most significant technical products or advances in each year. The following table shows the R\&D 100 Awards received by the three laboratories in 1996. 
Table I

1996 R\&D 100 Awards

\author{
NREL Automobile Exhaust Catalytic Converter \\ PNNL SPIRE ${ }^{\star}$ (Spatial Paradigm for Information \\ Retrieval and Explanation Software) \\ Liquid Multilayer/Polymer Processes for \\ Vacuum Deposition of Polymer Films \\ CEO - Catalyzed Electrochemical Oxidation \\ Autonomous Environmental Sentinel - AES \\ LANL PLASMAX (Plasma Mechanical Cleaner for \\ Silicon Wafers) \\ TRACER (Transportable Remote Analyzer \\ for Characterization and Environmental \\ Remediation
}

\title{
Contractor Performance Self-Assessments
}

In response to the Results Act and performance-based contracting, the Department and the three laboratories built upon these traditional peer review practices and instituted peer review as a formal part of the contractors' self-assessments and the Department's performance evaluation process. In this regard, NREL, PNNL, and LANL incorporated peer review into their performance self-assessment processes.

For example, the laboratories relied on peer reviews by external Division Review Committees to provide independent assessments of R\&D activities. At NREL, peer reviews were conducted on all technical work resulting from the Photovoltaics Program. These reviews were performed by Division Review Boards, Program Review Committees, and Standing Advisory Committees. All board and committee members were independent, third-party reviewers drawn from the university and industry community. Similarly, independent reviews were conducted on other NREL programs. Results from these reviews were incorporated into self-assessment reports that were provided to the Department for use in their annual performance evaluation of the laboratory. 
In another case, the Department's Richland Operations Office teamed with PNNL to develop mutually agreed-on performance objectives and indicators. Independent Division Review Committees were formed to review and evaluate the laboratory's major programs/projects, and evaluate the core technical capabilities, product lines, and technologies. For example, the Energy Technology Division Revision Committee for PNNL was comprised of individuals external to the laboratory representing academia, industry, government, and other national laboratories. The division review committees at PNNL were intended to complement, but not replace, other technical reviews required by the sponsors of the program.

The Los Alamos National Laboratory also has an annual science and technology assessment program. Assessments are performed by independent Division Review Committees selected by the laboratory director. Participants are selected from the private sector, universities, and Federal laboratories based on the breadth of their experience, expertise, and ability to understand the full spectrum of division activities. The results of the LANL self-assessment are provided to the University of California's President's Council on National Laboratories and to the Albuquerque Operations Office for use in the annual contractor performance evaluation.

The Department uses contractor self-assessment results as a part of its annual contractor evaluation and appraisal process. Other components of the Department's appraisal process include an evaluation of Laboratory Management; Environmental, Safety and Health; and Science and Technology. The Department evaluates and provides scores to these areas to calculate the contractor's annual rating. These scores determine salary increase multipliers, performance-based fees, and/or award fees.

Peer Review As An R\&D Management Tool
Independent reviews were used to provide data for program direction, obtain input, and prioritize research projects. To illustrate, based on the recommendations of the National Research Council, Environmental Management's Office of Science and Technology entered into an agreement with the American Society of Mechanical Engineers to provide independent and timely peer review over the development of environmental management technologies. The implementation of this recommendation resulted in the Department obtaining third-party reviews of research proposals, interim reports, and final reports. 
Peer review was also used by DOE program managers to obtain input on ongoing programs. For example, the results of a peer review on the Atmospheric Radiation Measurement Program (ARM) addressed questions PNNL had regarding program design, execution, and management. Third-party external reviewers provided comments on the objectives and strategies of the program and how they had evolved since the program's inception, whether the level of expenditure was consistent with the scientific significance of the program, and whether data management was sound. The external review resulted in an emphasis being placed on properly identifying which scientific tests were to be performed, an increase in the interaction with satellite programs, and a recommendation to have one of the ARM sites designated as a user facility.

Merit review with peer evaluation was, in addition, used to prioritize projects. As an example, in July 1995, the Office of Energy Research coordinated a peer review of 115 research projects sponsored by the National Photovoltaics Program. The purpose of the review was to determine the quality of individual research projects, the impacts of these individual projects on the mission of the program, and the priority of future research opportunities. A group of 100 technical experts formed 15 panels, and the panels were each assigned between 7 and 9 projects for review. Based on the results of the review panels, 13 projects with serious deficiencies were terminated.

The Value of Peer Review
We discussed the value of the DOE peer review process with members of peer review committees. Committee members, on the whole, held the laboratories' peer review programs in very high regard. Members who were interviewed identified three characteristics that distinguished peer review processes of Department of Energy funded R\&D from their other peer review experiences.

First, committee members stated that, in Departmental peer reviews, adequate information was given to tie the project or program under review to the current organizational mix, and ultimately, to whether there was value in the project to the Department. One committee member noted that during NREL Peer Reviews sufficient time was spent examining the mission of the Department; tying it to the current organizational mix; reviewing specific projects; and then making a determination of the value of the project to the Departmental mission. This contrasted with the experiences of the committee members who had participated in non-Departmental peer reviews. In their opinion, 
these other reviews did not provide enough information to put the research project or program in a larger context.

Second, interviewed peer review committee members agreed that the Department and the laboratories were responsive to recommendations. A member of the LANL committee commented on the high regard that management placed on comments of the peer review committee. This individual noted that they were pleased to see that recommended adjustments to a program had been implemented in response to a prior review, even though there had been "some severe comments." Similarly, NREL and PNNL committee members noted that recommendations were "seriously responded to" or "taken into consideration with appropriate changes made in the direction of research."

A third characteristic that provided value to the Department's peer review process was that committees were comprised from diverse and multiple disciplines. A PNNL committee member noted that the "multidisciplinary team approach led to free and open review and analysis of an entire program." Similarly, committee members from LANL also commented that the "diversity of disciplines on peer review committees provided for a more thorough and in depth review capability than available for other peer reviews."

This report does not contain recommendations since the three laboratories had established peer review processes. No exceptions or issues that required management's attention were identified as a result of applying the audit procedures to the specified lines of effort. The results of this audit are not projectable to other research and development projects, lines of effort, or Departmental programs. 


\section{SCOPE}

The audit examined the peer review process for research and development (R\&D) activities at three Department of Energy laboratories: Los Alamos National Laboratory (New Mexico), the National Renewable Energy Laboratory (Colorado), and Pacific Northwest National Laboratory (Washington). In Fiscal Year 1996, the Department's R\&D effort totaled about $\$ 6.7$ billion. Of that amount, about $\$ 4.5$ billion was allocated to the Department's laboratories. The remaining $\$ 2.2$ billion was allocated to Departmental field and operations offices research efforts.

Sites were selected and included in the review on the basis of whether or not the laboratory received funding for more than one program and whether line item funding was significant. The laboratories selected for review received $\$ 653$ million of the $\$ 4.5$ billion budgeted for $R \& D$ in Fiscal Year 1996. The following table shows the R\&D line item selected for review and the respective program/project, laboratory, and Fiscal Year 1996 budget amount.

Table II

\section{$\underline{\text { R\&D Program/Projects Selected for Review }}$}

\begin{tabular}{|c|c|c|c|c|}
\hline & R\&D Line Item & Program/Project & $\underline{\text { Lab }}$ & FY96 Budget \\
\hline DP & Stockpile Stewardship & $\begin{array}{l}\text { Nuclear Weapons } \\
\text { Technology }\end{array}$ & LANL & S $374,440,000$ \\
\hline EE & Energy Conservation & $\begin{array}{l}\text { Transportation } \\
\text { Sector }\end{array}$ & NREL & $44,991,000$ \\
\hline $\mathrm{EE}$ & $\begin{array}{l}\text { Solar \& Renewable } \\
\text { Energy }\end{array}$ & $\begin{array}{l}\text { Photovoltaic Energy } \\
\text { Biofuels/Biopower }\end{array}$ & $\begin{array}{l}\text { NREL } \\
\text { NREL }\end{array}$ & $\begin{array}{l}38,000,000 \\
20,390,000\end{array}$ \\
\hline ER & $\begin{array}{l}\text { Biological \& } \\
\text { Environunental }\end{array}$ & $\begin{array}{l}\text { Biological \& } \\
\text { Environmental }\end{array}$ & PNNL & $96,986,000$ \\
\hline EM & Technology Development & $\begin{array}{l}\text { Technology } \\
\text { Development }\end{array}$ & PNNL & $21,178,000$ \\
\hline NN & $\begin{array}{l}\text { National \& International } \\
\text { Security }\end{array}$ & $\begin{array}{l}\text { Nonproliferation \& } \\
\text { Verification R\&D }\end{array}$ & LANL & $\underline{57,445,000}$ \\
\hline & & & TOTAL & $\$ 653,430,000$ \\
\hline
\end{tabular}

TOTAL $\$ 653,430,000$ 
To accomplish the audit objective, Federal regulations related to peer review were examined to determine their applicability to laboratory operations. A White House, Office of Science and Technology Policy, and Office of Management and Budget memorandum on Fiscal Year 1996 R\&D policy principles and budget guidance was reviewed to identify the Administration's directive with regard to peer review. In addition, a Department of Energy "white paper" was analyzed to determine whether the report identified problems in Departmental peer review practices. Policies, procedures, and contractual requirements were obtained to determine peer review procedures and requirements included in $\mathrm{M} \& \mathrm{O}$ contracts. Finally, scientific research performance measures and criteria from the Department's Report of the Contract Reform Team were reviewed for their applicability to the DOE contracts with $\mathrm{M} \& \mathrm{O}$ contractors included in this review.

Listings of projects, programs, associated dollar amounts, and peer reviews performed were obtained at each of the three sites; and peer review practices were examined for projects with the highest dollar value. Selected projects were discussed with responsible scientists and managers who provided information on the purpose of the project or program, whether the project had been subject to either in-house or external peer review, and if the results of the review were used to guide the R\&D effort. Listings were also obtained of program-related articles and conference proceedings that had been subject to peer review.

Discussions were held with Headquarters, field and operations office, and contractor officials who provided information regarding peer review practices, contractor performance self-assessments, and applicable contract clauses. Meetings were also conducted with Headquarters and contractor finance officials to obtain budget and reporting categories, specific program/project titles, as well as cost and funding amounts on programs selected for review. Technology managers, scientists, program managers, and others responsible for managing the $R \& D$ programs and projects at the laboratories met with the audit team to provide information on peer review practices specific to their projects and programs.

Finally, the audit team contacted peer review members to obtain their views on whether the peer review process was worthwhile and if their results were utilized. Fieldwork for the review was conducted from August to November 1997.

The audit was conducted in accordance with generally accepted Government auditing standards for performance audits, which included tests of internal controls and compliance with laws and regulations to the extent necessary to 
satisfy the objectives of the audit. Internal controls were evaluated with respect to controls over peer review of Departmental R\&D projects.

Because the review of internal controls was limited, it would not have disclosed all internal control deficiencies that may have existed.

Computer-processed data was only used to select the sites and projects included in the review; therefore, an assessment was not made regarding the data's reliability or accuracy. 
Listed below are some of the peer reviews conducted during Fiscal Year 1996 at the National Renewable Energy Laboratory, the Pacific Northwest National Laboratory, and the Los Alamos National Laboratory. Departmental programmatic or internal reviews conducted by the laboratories are not included.

\section{National Renewable Energy Laboratory}

Photovoltaic Energy Program

Biofuels/Biopower

Demonstration Projects

Hybrid Electric Vehicles

Alternative Fuels Utilization

Alternative Fuels Utilization

Biofuels Program
NREL Photovoltaics Advisory

Committee

Science \& Industry Review

Committee

NREL Staff - Observe Project

Development - Advise DOE

National Research Council Through its ongoing review of the Partnership for New Generation Vehicles

NREL Staff - Monitor subcontracts/Advise DOE

Coordinating Research Council

Ethanol Project Technical

Review Panel

\section{Pacific Northwest National Laboratory}

Tanks Focus Areas Review

Tanks Focus Area - Technical Review Group 


\section{Los Alamos National Laboratory}

Nuclear Weapons Technology/ Proton Radiography

Nuclear Weapons Technology

Nonproliferation and

International Security Division
JASON - The Mitre Corporation

Physics Division Review

Committee

Nonproliferation and

International Review Committee 


\section{CUSTOMER RESPONSE FORM}

The Office of Inspector General has a continuing interest in improving the usefulness of its products. We wish to make our reports as responsive as possible to our customers' requirements, and, therefore, ask that you consider sharing your thoughts with us. On the back of this form, you may suggest improvements to enhance the effectiveness of future reports. Please include answers to the following questions if they are applicable to you:

1. What additional background information about the selection, scheduling, scope, or procedures of the audit would have been helpful to the reader in understanding this report?

2. What additional information related to findings and recommendations could have been included in this report to assist management in implementing corrective actions?

3. What format, stylistic, or organizational changes might have made this report's overall message more clear to the reader?

4. What additional actions could the Office of Inspector General have taken on the issues discussed in this report which would have been helpful?

Please include your name and telephone number so that we may contact you should we have any questions about your comments.

Name

Date

Telephone

Organization

When you have completed this form, you may telefax it to the Office of Inspector General at (202) 586-0948, or you may mail it to:

Office of Inspector General (IG-1)

Department of Energy

Washington, DC 20585

ATTN: Customer Relations

If you wish to discuss this report or your comments with a staff member of the Office of Inspector General, please contact Wilma Slaughter at (202) 586-1924. 
The Office of Inspector General wants to make the distribution of its reports as customer friendly and cost effective as possible. Therefore, this report will be available electronically through the Internet at the following alternative address:

Department of Energy Human Resources and Administration Home Page http://www.hr.doe.gov/ig

Your comments would be appreciated and can be provided on the

Customer Response Form attached to the report.

This report can be obtained from the

U.S. Department of Energy

Office of Scientific and Technical Information

P.O. Box 62

Oak Ridge, Tennessee 37831 